\title{
Stigma in women living with HIV in Coimbatore District of TamilNadu
}

\author{
Lingaraj Chitra ${ }^{1}$, Lingaraj Jayalakshmi ${ }^{2}$, Ramya Vinod ${ }^{3}$ \\ ${ }^{I}$ (Department of OBG, College Of Nursing, Sri Ramakrishna Institute of Paramedical Sciences, \\ Coimbatore,TamilNadu India) \\ ${ }_{2}^{2}$ (Department of physiology, Vydehi Institute of medical Sciences and Research Centre, Bangalore, \\ Karnataka,India) \\ ${ }^{3}$ (Department of Statistics, College of Nursing, Sri Ramakrishna Institute of Paramedical Sciences, Coimbatore, \\ TamilNadu, India)
}

\begin{abstract}
Stigma in patients living with HIV (PLWHIV) is an important factor influencing the non disclosure of disease as well as treatment. Stigma levels were measured in 43 Women living with HIV/AIDS, in Coimbatore district, Tamilnadu, India. Scores in the 4 domains of stigma-Personalized stigma, Disclosure stigma, Negative self-image and Public attitude stigma were calculated using the standardised Berger scale. Overall mean scores of each of the four forms of stigma was calculated. Scores in each domain were split into three levels - low, moderate and high and the percentage of patients in each level was calculated. High mean scores and percentage of women scoring high stigma levels was found for disclosure stigma followed by public attitude concern stigma. Negative self image showed the least stigma score. Correlation of scores with demographic data showed that socioeconomic status had significant negative relationship with Disclosure, concern with public attitude and with Overall Score. Interventions to improve quality of life in PLWHIV and to achieve better outcomes should focus more on reducing disclosure stigma and perceived public concern stigma along with education of Public against discrimination. Program evaluation should be done in a larger scale .
\end{abstract}

Keywords: Berger, Coimbatore, HIV, stigma, Women.

\section{Introduction}

India is estimated to have the third largest number of people with Human immunodeficiency Virus (HIV) in the world with a prevalence of 2.1 million [1]. and the WHO report on India has shown that of the HIV patients eligible for Anti retrovirus therapy(ART) only 50\% were receiving ART treatment in 2012 which showed no improvement from the ART coverage in 2011(50\%) [2]. Even among those receiving ART, adherence to treatment is another factor influencing the health outcomes in HIV patients.

U.N. Secretary General Ban Ki Moon has stated in 2008 "Stigma remains the single most important barrier to public action. It is a main reason why too many people are afraid to see a doctor to determine whether they have HIV, or to seek treatment" [3]. A systematic review analysis on 72 studies worldwide has reported a positive correlation of stigma in HIV patients with non adherence to treatment $[4,5]$.

Stigma has been described by Goffman as an "attribute that is deeply discrediting" imposed by society that reduces someone "from a whole and usual person to a tainted, discounted one'[6]. Stigma has numerous negative psychological, interpersonal, and societal consequences. [7]. It is among the most pervasive of the psychosocial issues and has been described as one of the greatest barriers to dealing effectively with the epidemic worldwide[8]. Stigma is manifested through four factors: prejudice, discounting, discrediting, and discrimination [9].

There are different domains of stigma- personalized stigma, stigma felt due to fear of consequences of others knowing of one's HIV status; [10,11]. Disclosure concerns, fear of disclosing one's own HIV status and fear that those who know would tell others. It drives HIV out of the public sight, introduces a desire not to know one's own status, thus delaying testing and access treatment and possibly increasing the risk of infection; [12,13,14]. Negative self-image, experiencing oneself as tainted and not as good as others because of one's HIV and concerns with public attitudes, conceptions of what people might think about a person with HIV or what 'most people' with HIV can expect when others learn they have HIV infection [15].

The attachment of gender discrimination to HIV stigma has led to women being blamed for spreading the epidemic. Women are contradictorily expected to provide sexual services to men, at the same time be chaste and pure and take on the responsibility of preventing the disease[16].

Studies in India have been done on stigma in HIV/ AIDS (acquired immunodeficiency syndrome) but most of them have been done in the general population and health care personnel, students etc and not in patients living with HIV/AIDS(PLWHA) . As stigma has a direct effect on care-seeking behaviour and outcome it must be assessed to optimize care for those infected and affected by HIV especially in Indian women. Also most of the 
studies in PLWHA are qualitative with very few quantitatively measuring stigma. Hence this study was done to identify and measure the experience of stigma by female PLWHA using the standard Berger stigma scale, a 40 item questionnaire for measuring stigma, based on the four forms of HIV related stigma Personalized/Internalized stigma, Disclosure stigma, Negative self-image and Public attitude stigma[17].

\section{Methods And Materials}

This is a descriptive survey that identified and measured the stigma experience of HIV positive women living in Coimbatore district. A purposive sample of 43 of Women living with HIV/AIDS, aged 20-50 years and residing in the town of Coimbatore in the state of Tamilnadu were recruited through the Coimbatore Network of Positive Persons(CNP+) which are support networks for HIV-positive individuals. The study was described to the women affiliated with these networks. Informed consent was obtained from all the women. Literate participants read the consent form themselves, while the interviewer read it out to those who were nonliterate. The interviewer administered the questionnaires as a face-to-face interview. The study was done with the approval of Coimbatore district program officer, Tamilnadu Aids Control Society (TANSACS).

Socio-demographic proforma comprised of baseline information regarding age, marital status, education, occupational status, number of children and type of family. The Berger HIV Stigma Scale: A standardized scale was used to measure stigma. The scale is a 40 items scale rated along a 4 point Likert scale (Strongly Disagree, Disagree, Agree, and Strongly Agree). Stigma experienced by an HIV-positive person is measured across four domains of stigma - Personalized Stigma(18 items), Disclosure Concerns(10 items), Negative Self-Image(13 items) and Public Attitude (20 items). There is an overlap of few items across the domains giving a total of 40 items. The scores for each domain varies with the number of items in the domain( 1 multiplied by number of items is the least score and 4 multiplied by number is highest score ). Least total score is 40 and highest total score is 160 . The higher the score the greater is the stigma. The questions were translated into Tamil. No changes were made to question phrasing. The average time required to administer the scale was $15-25$ minutes.

Statistical analysis was done using SPSS-16. The mean scores of each of the four forms of stigma experience were determined. Scores in each domain were split into three levels - low , moderate and high and the percentage of patients in each level was calculated. Correlations of the total stigma score and their subscales, (personalized stigma, Disclosure concerns, Negative self-image, and Concern with public attitudes) was determined. Pearson's correlation coefficients and independent $t$ test were computed for outcome measures.

\section{Results}

The mean age of the female respondents was 34 years and $85 \%$ were between 26 to 40 years. $97 \%$ women were currently married while $3 \%$ women were widowed. Most of the respondents $75 \%$ were living in joint families and $25 \%$ had nuclear families. The group was predominantly literate, with $90 \%$ of the respondents having undergone primary to middle school education. Nearly $90 \%$ of the women were working . $90 \%$ of the women had children. All of them belonged to very low socioeconomic group.

Mean score of stigma in all the four forms of stigma was above 60\% of the highest score for each domain with highest score for disclosure followed by public attitude(TABLE 1).

Table 1Mean scores of various domains of stigma experienced by women with HIV

\begin{tabular}{|l|l|l|l|}
\hline $\begin{array}{l}\text { Stigma Domain (score least - } \\
\text { highest) }\end{array}$ & $\begin{array}{l}\text { Minimum score } \\
\text { recorded }\end{array}$ & $\begin{array}{l}\text { Maximum score } \\
\text { recorded }\end{array}$ & $\begin{array}{l}\text { Mean } \pm \text { SD (as \% of highest } \\
\text { score })\end{array}$ \\
\hline Personalized (18-72) & 25.00 & 62.00 & $46.8605 \pm 8.218(63)$ \\
\hline Disclosure (10-40) & 14.00 & 37.00 & $28.2093 \pm 5.1388(70)$ \\
\hline Negative Self-image (13-52) & 17.00 & 41.00 & $31.3488 \pm 4.8250(60)$ \\
\hline Public Attitudes (20-80) & 31.00 & 66.00 & $53.0930 \pm 9.1308(66)$ \\
\hline $\begin{array}{l}\text { HIV Stigma Overall Score (40- } \\
\text { 160) }\end{array}$ & 61.00 & 127.00 & $105.7200 \pm 15.1929(66)$ \\
\hline
\end{tabular}

Frequency distribution of patients in low, moderate and high stigma levels showed that majority of patients were in moderate level. So this level was further split as low moderate and high moderate (TABLE 2). The number of patients in high moderate and high stigma level were 25(58.1\%), 32(74.4\%), 20(46.4\%) and $29(67.4 \%)$ for personalized stigma, Disclosure concerns, Negative self-image and Concern with public attitudes respectively.

Correlation analysis of individual domain scale with total scale showed that all the domains were correlated with total stigma scale scores $(\mathrm{p}<0.05)$. Correlation of age and income showed that income variable had significant negative relationship with Disclosure, concern with public attitude and with Overall Score 
$(p<0.05)$. There was no correlation with age. Independent $t$ test for categorical demographic variables (number of children, type of family, education) did not show any statistical significance.

Table 2-Frequency distribution of respondents on HIV Stigma score level

\begin{tabular}{|c|c|c|c|}
\hline Stigma type & \begin{tabular}{|l|} 
Score \\
Level
\end{tabular} & Score value & $\begin{array}{l}\text { Frequency }(\%) \\
\mathrm{N}=43\end{array}$ \\
\hline \multirow[t]{4}{*}{ Personalized } & Low & $18-36$ & $4(9.3)$ \\
\hline & \multirow{2}{*}{$\begin{array}{l}\text { Moderate } \\
37-54\end{array}$} & $37-45$ & $14(32.5)$ \\
\hline & & $46-54$ & $17(39.5)$ \\
\hline & High & $55-72$ & $8(18.6)$ \\
\hline \multirow[t]{4}{*}{ Disclosure } & Low & $10-20$ & $4(9.3)$ \\
\hline & \multirow{2}{*}{$\begin{array}{l}\text { Moderate } \\
21-30\end{array}$} & $21-25$ & $7(16.3)$ \\
\hline & & $26-30$ & $16(37.2)$ \\
\hline & High & $31-40$ & $16(37.2)$ \\
\hline \multirow[t]{4}{*}{ Negative Self-image } & Low & $13-26$ & $4(9.3)$ \\
\hline & \multirow{2}{*}{$\begin{array}{l}\text { Moderate } \\
27-39\end{array}$} & $27-32$ & $19(44.1)$ \\
\hline & & $33-39$ & $19(44.1)$ \\
\hline & High & $40-52$ & $1(2.3)$ \\
\hline \multirow[t]{4}{*}{ Public Attitude } & Low & $20-40$ & $4(9.3)$ \\
\hline & \multirow{2}{*}{$\begin{array}{l}\text { Moderate } \\
41-60\end{array}$} & $41-50$ & $10(23.2)$ \\
\hline & & $51-60$ & $18(41.8)$ \\
\hline & High & $61-80$ & $11(25.6)$ \\
\hline \multirow[t]{4}{*}{ HIV Stigma Overall } & Low & $40-80$ & $3(7)$ \\
\hline & \multirow{2}{*}{\begin{tabular}{|l} 
Moderate \\
$81-120$
\end{tabular}} & $81-100$ & $11(25.6)$ \\
\hline & & $101-120$ & $22(51.1)$ \\
\hline & High & $121-160$ & $7(16.3)$ \\
\hline
\end{tabular}

\section{Discussion}

This study was done to measure the stigma in women living with HIV in Coimbatore district of TamilNadu using the standardized Berger stigma scale. The overall mean stigma score was 105.7 \pm 15.1929 which is similar to the overall score of $109.6( \pm 16.2)$ in a Chennai based study done using the same scale [18]. In another study on Nigerian men and women, females were found to experience more stigma (mean score $=107.32$ ) when compared with male patients (mean score=101.46) [11].

In the present study subscale scores for the sigma domains showed highest score for disclosure stigma followed by public attitude concern. Negative self image showed the least scores. In comparison with a study done in Democratic Republic of the Congo (DRC) and presented in international association of AIDS conference disclosure stigma was highest followed by personalized stigma. [19]. But in the Nigerian study personalised stigma and public attitude stigma were found to be higher in females than disclosure stigma. Negative self image was the last in both the studies[11].

Various studies from developing world have reported non disclosure stigma to be higher when compared to the developed world studies. \% of disclosure varied from $10 \%$ in Thailand to $77.8 \%$ in Tanzania High disclosure stigma and ensuing non disclosure could be possibly due potential risks of disclosure to sexual partners including - Loss of economic support, Blame, Abandonment, Physical and emotional abuse, Discrimination, Disruption of family relationships .Another potential risk of disclosure is the possibility that children may face violence or abandonment as a result of their parent's disclosure of their positive status whether or not the children are also positive[cross ref 20].

The present study has shown significant negative correlation of income with disclosure stigma and with public attitude concern stigma. A South African study done on risk factors associated with disclosure stigma reported that the odds of disclosing status for women with high income were 3.25 times higher when compared to women with lower income. Higher income and higher socio-economic status seems to reduce fear of abandonment by a partner and family, leading to increased rates of disclosure[21].

Public attitude stigma which is also higher in this study is probably stigma felt or perceived from other people living with HIV or from those associated with PLWHIV. Perceived stigma occurs when there is a real or imagined fear of societal attitudes regarding a particular condition. Community discrimination on HIV patients 
plays an important role as shown by studies reporting public opinion on HIV patients stating that the public would not buy vegetables or fruits from an HIV/AIDS patient, a HIV/AIDS positive teacher should not be allowed to teach even though they may not be sick and that they(public) will not allow their children to play with a child infected with HIV/AIDS. Regardless as to whether a person has objectively experienced HIV stigma, the perception of HIV stigma appears to be strongly related to the negative outcomes Individuals with high levels of perceived social support have been found to have a more positive approach towards life and those with lack of perceived social support can have negative consequences. [22].

Negative and personalised stigma scores were comparatively lesser and could be due to their belief that their self morality and dignity is intact and they are not at fault for the acquiring or consequences of HIV.

Limitations of this study - Even though the results are correlating with other studies the sample size of this study should have been higher for better analysis and extrapolation.. Participants were only women part of the network and does not include isolated women. Also the demographic data did not indicate the number of years the patients had HIV.

\section{Conclusion}

The 2012 -13 National Aids Control Organization (NACO) report says that one of the key priorities of the $4^{\text {th }}$ NACP for 2012 -17 (National Aids Control Program ) is reducing stigma and discrimination through Greater Involvement of People living with HIV (GIPA) . To improve quality of life in PLWHIV especially women and to achieve good results and better outcomes, more focus should be on interventions reducing disclosure stigma and perceived public concern stigma along with education of Public against discrimination. Program evaluation should be done to assess stigma levels and the effect of the interventions in a larger scale .

UNAIDS, GAP REPORT 2013 http://www.unaids.org/.

[2]. Global Update On Hiv Treatment $2013: 2013$; (June)

[3]. Ban Ki-Moon. The Stigma Factor: Biggest Hurdle To Combat Hiv/Aids The Washington Times (Us) 06 August 2008

[4]. Unaids (2010). Global Report: Unaids Report On The Global Aids Epidemic (2010). [Online] Www.Unaids.Org/Globalreport/Documents/20101123_Globalreport_Full_En.Pdf

[5]. Katz IT, Ryu AE, Onuegbu AG, Psaros C, Weiser SD, Bangsberg DR, et al. Impact of HIV-related stigma on treatment adherence: systematic review and meta-synthesis. 2013;16(Suppl 2).

[6]. Goffman, E. (1963). Stigma: Notes On The Management Of Spoiled Identity. Englewood Cliffs, Nj: Prentice Hall.

[7]. Green, G., \& Platt, S. (1997). Fear And Loathing In Health Care Settings Reported By People With Hiv. Sociology Of Health And Illness, 19(1), 70-92.

[8]. Li Li, Sung-Jae Lee And Mary Jane Rotheram-Borus, Stigma, Social Support And Depression Among People Living With Hiv In Thailand Aids Care,Aug 2009;21(8):1007-1013

[9]. Herek GM. Fight AIDS\&mdash;Not People with AIDS! 2009http://psychology.ucdavis.edu/rainbow/HTML/aids.htm

[10]. Wiklander M, Rydström L-L, Ygge B-M, Navér L, Wettergren L, Eriksson LE. Psychometric properties of a short version of the HIV stigma scale, adapted for children with HIV infection. Health Qual Life Outcomes [Internet]. 2013 Jan;11:195. Available from: http://www.pubmedcentral.nih.gov/articlerender.fcgi? artid $=3842678 \&$ tool $=$ pmcentrez \& rendertype $=$ abstract

[11]. Blessed NO, Ogbalu AI. Experience of HIV-related stigma by people living with HIV / AIDS ( PLWHA ), based on gender: A case of PLWHA attending clinic in the Federal Medical Center, Owerri ,. 2013;5(November):435-9.

[12]. Shapiro RL (2003). Low adherence to recommended infant feeding strategies among HIV-infected women: results from the pilot phase of a randomized trail to prevent mother-to- child transmission in Botswana. AIDS Educ. Prev. 15(3):221-30.

[13]. Spiegel P (2004). HIV/AIDS among conflict-affected and displaced populations: dispelling myths and taking action, Disasters. http://www.unher.ch.cgibin/texix/vtx/protect/opendoc.

[14]. United Nations Programme on HIV/AIDS (2006). Comprehensive HIV prevention and reports on Global AIDS Epidemic 06:124. Geneva.

[15]. Lichtenstein B (2003). Stigma as a barrier to treatment of sexually transmitted infection in the American Deep South; Issues of race,gender and poverty. Soc. Sci. Med. 57(12):2435-2445.

[16]. Leclerc-Madiala S (2002). Youth, Hiv/Aids. Youth And The Importance Of Sexual Culture And Context. Social Dynamics. J. Afr. Stud. 28(1):20-41.

[17]. Barbara E. Berger,Carol Estwing Ferrans,Felissa R. Lashley. Measuring stigma in people with HIV: Psychometric assessment of the HIV stigma scale. Research in Nursing \& Health. Volume 24, Issue 6, pages 518-529, December 2001

[18]. J, eyaseelan.L,Shuba Kumar, Rani Mohanraj, Grace Rabekah, Deepa Rao, Lisa. AIDS Behav.Abridgement of the Berger HIV Stigma Scale. 2014;17(1):434-43.

[19]. MupendaB, Holub C, Pettifor A ,. KashosiM, Taylor E, Duvall Setal Informing measures for positive prevention: perceived stigma, depression and social support among youth living with HIV/AIDS in Kinshasa, Democratic Republic of the Congo (DRC) conference presentation http://www.iasociety.org/abstracts/a200718879.aspx

[20]. Suzanne Maman and Amy Medley.Gender Dimensions of HIV Status Disclosure to Sexual Partners: Rates Barriers and Outcomes Gender Dimensions of HIV Status Disclosure to Sexual Partners: Rates, Barriers and Outcomes Department of Gender and Women 's Health ( GWH ).

[21]. Longinetti E, Santacatterina M, El-Khatib Z. Gender perspective of risk factors associated with disclosure of HIV status, a crosssectional study in Soweto, South Africa. PLoS One [Internet]. 2014 Jan [cited 2014 Nov 26];9(4):e95440. Available from: http://www.pubmedcentral.nih.gov/articlerender.fcgi? artid=3990640\&tool=pmcentrez\&rendertype $=$ abstract

[22]. Galvan FH, Davis EM, Banks D, Bing EG. HIV stigma and social support among African Americans. AIDS Patient Care STDS [Internet]. 2008 May [cited 2014 Nov 26];22(5):423-36. Available from: http://www.pubmedcentral.nih.gov/articlerender.fcgi? artid=2831751 \&tool=pmcentrez\&rendertype $=$ abstract 